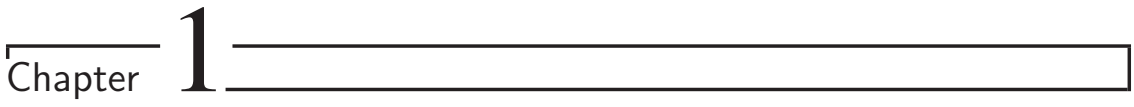

\title{
Accuracy of the win odds
}

The crowd is composed of many types of bettors. Most of the people attending a day's card, particularly on Saturdays and Sundays, do not go to the track all that frequently. They go every so often to enjoy a good day's racing and to have an entertaining afternoon or evening. They do not expect to win but they certainly would enjoy a winning day and particularly a big exciting payoff. These bettors have many systems for their betting. Many just follow the picks in the program, the daily racing form's consensus or from one of the tip sheets. Others study the daily racing form with great care and attempt to find overlaid horses going off at odds that are longer than they should be. Others make bets by the way the horses look in the post parade. Some base their choices on favorite numbers like seven in the seventh and names like Lucky Lucky Lucky. Some bet the same amount in every race. Others mix up their bets reserving the larger bets for the horses that look the best.

Most tracks also have a large number of regulars who may number in the thousands. These bettors come to the track two, three, four or more times a week. They might go to more than one track on the same day such as the thoroughbreds in the afternoon and the trotters in the evenings. Most of these regulars are quite serious about their betting. Many keep detailed records of various horses, trainers, jockeys, and track conditions. This can include speed ratings, track variants, post position biases, trainer's intentions forecasts, trip handicapping and the like. The regulars bet all types of amounts and wagers. Serious amateur handicappers prefer to bet to win. They also like the action in the exotics, particularly the exacta select the first two finishers in exact order; and the triactor - select the first three horses in exact order. Handicappers tend not to like quinellas - select the first two finishers without regard to the order of finish; the double the winners of the day's first two races or any consecutive races; the pick 
six and pick nine select the winners of six or nine consecutive races; nor place and show betting. Quinellas do not pay enough they reason. Doubles are considered to be a sucker bet because you have to handicap the second race before the first race is even run and the pools for race 2 are basically unknown. The pick six and the pick nine are considered too tough to win. It's hard enough to pick the winner in one race let alone to pick six or nine in a row. Sure the payoffs are high but the chance of winning is so small that it's like a lottery and we leave lottery bets to those who want to give away their money, so they say. Also the $\$ 2$ tickets are expensive so one needs large tickets costing more than $\$ 1000$ to have a decent chance of winning. Hence Pick 4 with $\$ 1$ tickets and fewer races is more popular. Place and show bets are not much fun and the payoffs are too small to win anything. They feel that the advice in most handicapping books is good advice: you will have to collect half or more of the time betting to place and more often betting to show just to break even and with the low payoffs the breakage will wipe you out in the long run.

Finally there are the professionals. A top track may have a hundred or more of them. They do all the above and more. Over the years they acquire a deep understanding of horses and the entire racing game. Most professionals are very disciplined. They have to be; after all racing is their profession and possibly their livelihood. Their bets are carefully considered. Bets are not made in every race but only when a situation looks outstanding. Professionals may have bankrolls in the several hundred thousand range and make bets of several thousands or even millions dollars or more on a single situation. Some professionals are skilled in money management techniques, however, most rely on superior handicapping for their success. Many professionals are quite open about their selections and methods; others are quite secretive. A subset of these bet millions in syndicates using large teams of researchers, computers and others with various skills. They bet a lot and can move the odds considerably.

The crowd is thus a conglomerate of many many betting types with varying degrees of knowledge of the horses and the racing game. Some bet very small amounts such as $\$ 2$ per race. Others bet thousands when a situation looks outstanding. Some use elaborate information, others hardly any. What do we really know about them? The evidence points to several conclusions:

1. It is very very difficult to beat the races; the $15-18 \%$ track take plus breakage for straight bets and $17-25 \%$ track take plus breakage on exotic bets is extremely difficult to overcome; less than one in a hundred regular bettors is ahead in the long run. 
2. The odds set by the crowd, despite the vast differences among the betting styles, are actually very accurate; on average the chance that a given horse will win a race is very close to what the crowd as a consensus thinks it is.

3. The crowd has a considerable bias against favorites and for longshots. The thrill and bragging rights are just not there by wagering on short odds favorites, hence they are shunned and are considerably underbet. Longshots on the otherhand are the crowd pleasers and they are significantly overbet.

The fact that it is difficult to win is no surprise. Many bettors, including a good portion of the expert handicappers and professionals, are aware of conclusions (2) and (3). Some use these facts in their betting but most do not. Let's look at some actual data to try to nail this down more carefully.

\section{The favorite-longshot bias}

The favorite-longshot bias is the tendency in horseracing, sports betting, and financial options for the most likely outcome to be underbet and the less likely outcomes overbet. So people tend to like junk and dislike the best possibilities. This bias has been well known to Irish and other bookmakers who actually create the bias with the bets they offer for the last $100+$ years. Figure 1.1 shows the 1949 study by Griffith for 1386 races in 1947 for races at Churchill Downs, Belmont and Hialeah. In this graph, there are the number of entries, winners and winners times odds for every odds group. The axes show the odds, the subjective probabilities, versus the actual number of inners, the objective probabilities.

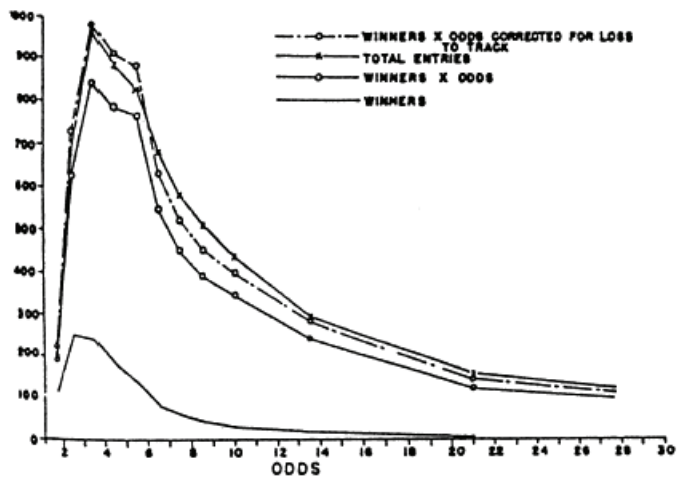

Figure 1.1: Griffith's 1949 study on the favoritelongshot bias; see Hausch, Lo and Ziemba (2008) for the reprinted paper. 
Figure 1.2 and Table 1.5 show these conclusions. They are based on 35,285 races at many different tracks during 1947-75 as summarized in Snyder (1978).

Figure 1.2: $\quad$ Expected Return Per Dollar Bet for Different Odds Levels, in 35,285 Races Run During 1947-1975. Source: Snyder (1978).

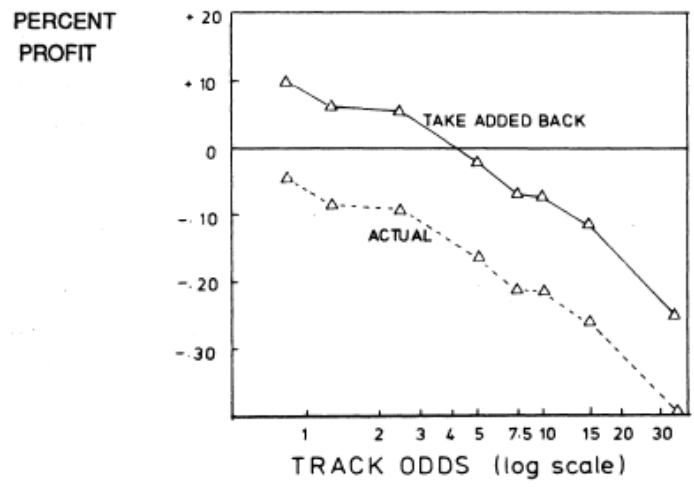

Table 1.1: Summary of the Six Studies Comparing the Rate of Return on Win Bets at Various Odds Levels; Source Snyder (1978).

\begin{tabular}{|c|c|c|c|c|c|c|c|c|}
\hline \multirow[b]{2}{*}{ Study } & \multicolumn{8}{|c|}{ Midpoint of grouped odds } \\
\hline & 0.75 & 1.25 & 2.5 & 5.0 & 7.5 & 10.0 & 15.0 & 33.0 \\
\hline Fabricant & $11.1^{a}$ & $9.0^{n}$ & $4.6^{\mathrm{a}}$ & -1.4 & -3.3 & -3.7 & -8.1 & $-39.5^{x}$ \\
\hline Griffith & 8.0 & 4.9 & 3.1 & -3.1 & $-34.6^{2}$ & $-34.1^{2}$ & -10.5 & $-65.5^{4}$ \\
\hline McGlothlin & $8.0^{h}$ & $8.0^{a}$ & $8.0^{u}$ & -0.8 & -4.6 & $-7.0^{\mathrm{h}}$ & -9.7 & -11.0 \\
\hline Seligman & 14.0 & 4.0 & -1.0 & 1.0 & -2.0 & -4.0 & -7.8 & -24.2 \\
\hline Snyder & 5.5 & 5.5 & 4.0 & -1.2 & 3.4 & 2.9 & 2.4 & -15.8 \\
\hline Weitzman & $9.0^{a}$ & 3.2 & $6.8^{\mathrm{a}}$ & -1.3 & -4.2 & -5.1 & $-8.2^{h}$ & $-18.0^{\prime \prime}$ \\
\hline Combined & $9.1^{2}$ & $6.4^{a}$ & $6.1^{3}$ & -1.2 & $-5.2^{u}$ & $-5.2^{n}$ & $-10.2^{a}$ & $-23.7^{\mathrm{i}}$ \\
\hline
\end{tabular}

"Significantly different from zero at $1 \%$ level or better.

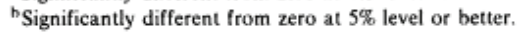

The favorite-longshot bias shows up very clearly in these large data sets. The longer the odds are, the lower the average return is. Referring to Figure 1.5 we see that at odds up to about 9-2, the expected return per dollar bet is higher than the track payback less breakage. After that point the return decreases as the odds increase. Also, as the odds become shorter the average return increases. At very short odds one even had slight profits. So let's look at extreme favorites. 


\title{
Betting to win usually leads to losses unless you have an edge
}

\author{
Hardly a man that's now alive paid a mortgage at 3-5 Harvey \\ Pack
}

Historically, betting to win usually leads to losses except on extreme favorites, but, as we see below, all bets for win, currently in 2016, on average produce losses.

On average, bets to win lose the track take and breakage. For each dollar wagered the bettors on average receive about $81-84$ cents. With an $84 \%$ return you have to pick winners about $19 \%$ more often than the average bettor to be even. With an $81 \%$ return it's even worse - you must be about $23.5 \%$ better than the average bettor just to break even. Except for the tail biases, the average bettor is not bad at all at picking winners. In fact, the crowd is very good at picking winners as they establish win odds that very accurately represent on average the true chances of horses winning at various odds levels, except for the tail biases. The crowd loves longshots and shuns favorites. So unless you are an expert handicapper your main hope of making profits betting to win is to concentrate on the favorites. For a typical favorite at $2-1$, you will do about $6 \%$ better than chance but you still will lose about 11\% in California and 13\% in New York. (With its lower track take, the payoffs in California are slightly higher than in New York.) As you pick greater and greater favorites you will do better and better on average. Not worse as many handicappers feel. But can you actually make profits? Let's look at some data.

Figure 1.9(a) shows the results of 1509 races run in 1955-1962 at various tracks where the favorite went off at odds of 2-5 to 6-5. This study by Fabricand $(1965,1979)$ shows that modest profits of $3.4 \%$ were made by those who bet the 2-5 shots. Losses started occurring at 3-5 and became greater and greater as the odds lengthened. At 6-5 the losses were already about $9 \%$. Figures 1.9 (b) and 1.9(c) which display the results for 233 races in New York in 1980 that went off at odds of 1-10 to even money and all the flat races in England during 1950, 1965 and 1973 show similar results. For the New York races, the breakeven point is at odds of 3-10 and 6\% profits were made on the 1-10 to 3-10 shots. At 2-5 the losses start and they accelerate as the odds lengthen. For the 7-10 to even money shots, losses already are about 13\%. Even the 2-5 to 3-5 odds group has losses of $6 \%$. In England the results are similar except that the $4 \%$ on-course tax lowers the profit rate to a measly $0.6 \%$. With the $8 \%$ off-course tax there are losses at all odds levels. 
Table 1.2: Probability of winning versus odds from win bets on extreme favorites in California and New York expected value using historical data.

\begin{tabular}{lrrrr} 
& \multicolumn{4}{c}{ Probability of winning, 1986 data } \\
Odds & CA & NY & CA & NY \\
$1-10$ & 92.0 & 90.5 & 105.0 & 103.3 \\
$1-5$ & 78.7 & 77.6 & 101.7 & 100.0 \\
$2-5$ & 65.7 & 64.6 & 97.7 & 96.0 \\
$3-5$ & 55.6 & 54.6 & 93.7 & 92.0
\end{tabular}

The conclusion on the historical data is that by betting on extreme favorites going off at odds of 1-10 to 3-10 modest profits of about 3-6\% could have been made in this 1986 period. Figures 1.3ab and Table 1.2 detail this and also provide the probability of winning each wager. Losses set in at about 2-5 and become larger and larger as the odds lengthen. These modest profits are not guaranteed, of course, since they are subject to statistical deviations. For the New York races two standard deviations, which is the usual measure used by statisticians to try to prove that profits really are positive, is a healthy $15 \%$. So a statistician would not be able to conclude even that the $6 \%$ was really not a statistical fluke. However, by combining the various samples one can demonstrate that there really were positive but fairly modest profits in betting 1/10 to 3/10 shots to win in 1986 .

However, as we see in the more recent figures below, this advantage no longer exists.

The optimal Kelly wager ${ }^{1}$ on one of these extreme favorites is very large. For example in New York, at 1-10 odds, the expected return per dollar wagered is $\$ 1.033$ so there is a 3.3\% edge. The optimal Kelly bet, assuming that you do not influence the odds is the edge divided by the odds which is $33 \%$ of one's bankroll. We recommend a smaller wager because of the uncertainties involved. A $50 \%$ fractional Kelly wager seems reasonable. At 1-5 the edge is zero in New York and only 1.7\% in California so the wager then would be small.

Betting horses to win can be profitable. Expert handicappers are doing it every day. What seems to be true though is that some sort of high level of expertise seems to be needed to win.

\footnotetext{
${ }^{1}$ The Kelly capital growth strategy is discussed in Chapter 4 . It leads to the bets that maximize final wealth most but not all of the time. The seminal application is to a long sequence of similar bets like we have here.
} 


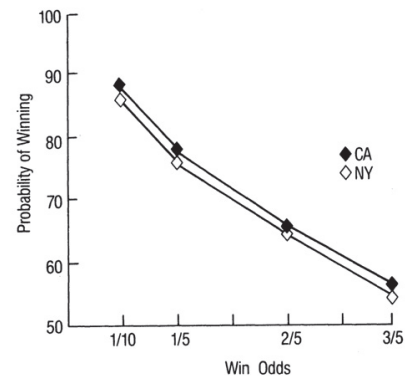

(a) Probability of Winning

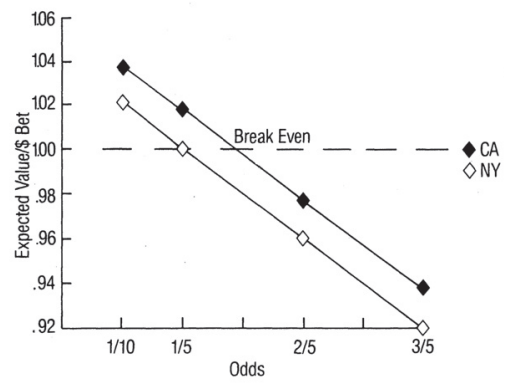

(b) Expected Value per Dollar Bet

Figure 1.3: Betting on Extreme Favorites in California and New York.

\section{Win, place and show across the board bets}

A standout often is a good across the board bet when the win odds are over even money. At less then even money, place bets are usually recommended as they price out with an advantage. In the 2013 Pacific Classic $\$ 1$ million $1 \frac{1}{4}$ race on a synthetic surface on Sunday August 25, 2013, Game on Dude was such a bet. By betting equal amounts to win, place and show, one is usually ahead if the horse is first, breaks even or has a slight profit with rebate if the horse is second and loses if the horse is third or worse. Game on Dude was the pick on the handicapping services HTR, PSR and had three Grade I wins since June 2012 with Beyer speed ratings over 110 and as high as 114, 117 and 116 in there of his last four wins. Mike Smith rode him to five wins since December 2012. Mike was at Saratoga riding Royal Delta to an easy win in a similar type of bet. So trainer, Bob Baffert's favorite jockey Rafael Berjano rode him. I made a small bet, $\$ 30$ win, place and show and an $8 \frac{1}{2}$ length win by Game on Dude over the likes of Farraaj, Richard's Kid, Kettle Corn, Dullahan, Delegation and Jeranimo paid 5.40, 3.80 and 3.20. The chart follows as does Game on Dude's record.

The favorite-longshot bias seems to show up in all reasonably large data sets. $^{2}$ It represents the way the public likes to bet. Figure 1.4 illustrates this further with data on all the British flat races from the years of 1950, 1965 and 1973. These data represent odds set by bookies. In England, one can bet by the totalizator system that uses parimutuel odds set by bettors as in North America. Alternatively, one can bet with legal bookies at the track (called on-course) or off the track (off-course). The tradition of the

\footnotetext{
${ }^{2}$ Exceptions are in low probability high payoff bets such as the Pick 6 where favorites are over bet and in certain Asian markets. Both of these are discussed later in this book.
} 
bookies stretches for hundreds of years and this is the preferred method of wagering in England. This has allowed the bookies - who also have lower overhead - to quote odds that have a much lower average take than the track. Their goal, of course, is to make as much profit as possible. To do this they must quote odds that the public likes so they will buy many many tickets. They must also more or less balance their books by having the bets spread around so that no matter which horse wins they do not take much of a loss. The odds ranges used by English bookmakers are quite different than those used in North America. At odds of $1 / 100$ to $2 / 5$ the expected return is $104.6 \%$ of the amount bet, at $4 / 9$ to $3 / 5$ the return is $99.3 \%$, at $8 / 11$ to $1 / 1$ it's $92.3 \%$, at $21 / 20$ to $3 / 2$ it's $90.8 \%$, at $13 / 8$ to $9 / 4$ it's $90.0 \%$, at $95 / 40$ to $4 / 1$ it's $95.3 \%$, at $9 / 2$ to $9 / 1$ it's $89.6 \%$, at $19 / 2$ to $18 / 1$ it's $65.3 \%$ and at odds greater than 18 to 1 it's $28.1 \%$. This creates the favorite-longshot bias seen in Figure 1.4.

Figure 1.4: Expected Value Per Dollar Bet for Different Odds Levels in all British Flat Races During 1950, 1965 and 1973. Taxes of $4 \%$ on-course and $8 \%$ off-course must be subtracted to give the actual return to bettors. Source: Figgis (1974) and Lord Rothschild (1978).

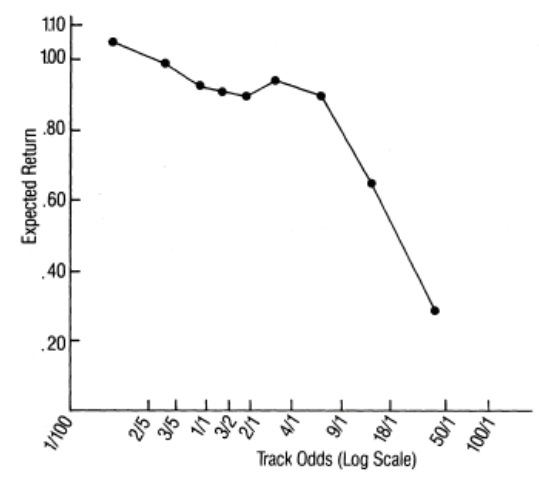

Notice that for the lowest odds horses the bookies actually take a LOSS. With the $4 \%$ on-course and $8 \%$ off-course government taxes, the bettors do not quite make a profit but it is close - they more or less break even. While losses progressively increase up to odds of 9-1, they are quite small. However, once the odds become 10-1 or more the average return per dollar bet drops sharply. In the 10-1 to 18-1 range, the average return is only $65 \%$. Then with the real longshots going off at odds of over 18-1, the average return is a measly $28 \%$. That means that for a $50-1$ shot you really should be getting about 200-1 to have a fair bet. The bookies can get away with giving this poor return because of the public's strong preference for betting on longshots. Part of the low return on longshots occurs because bookies limit the maximum payoff. The main reason, however, is that longshots simply come in a lot less than their odds would indicate. To get people to 
bet on the unpopular favorites, the bookies actually have to take smaller profits and even losses on the extreme standouts.

Figure 1.5 shows the effective track payback less breakage for various odds levels in California and New York, more than 300,000 races over various years and tracks, as of 1986 as reported in the original Ziemba and Hausch (1986) book, Betting at the Racetrack.

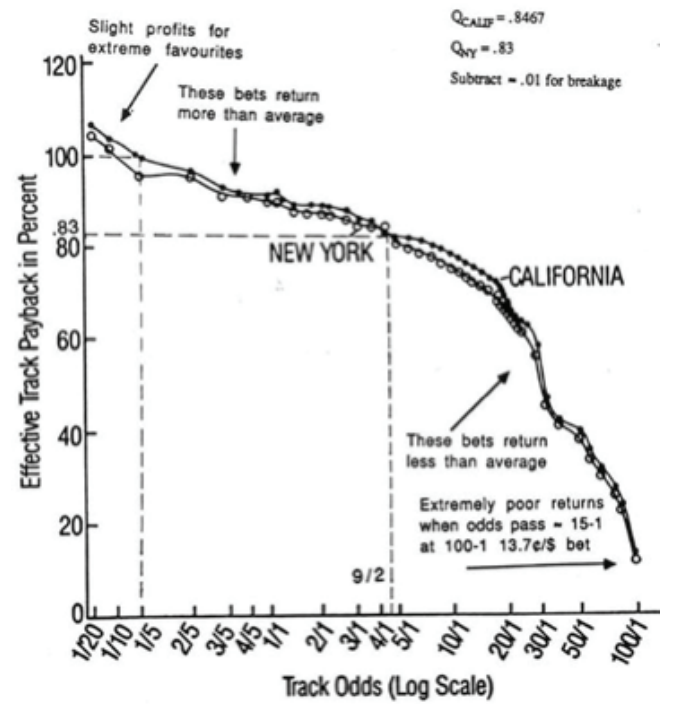

Figure 1.5: The effective track payback less breakage for various odds levels in California and New York (more than 300,000 races over various years and racetracks). Source: Ziemba and Hausch (1986).

Observe that there actually was a small profit in betting horses to win at US odds of 3-10 (UK odds of 1.30 or less). and that at odds of 100-1, the fair odds are about 700-1 so that such bets were worth about 13.7 cents per dollar bet. The California and New York graphs differ because of different track takes. There are approximately three piecewise linear segments, small profits on extreme favorites with favorites underbet and longshots overbet, more and more losses as the odds lengthen and extremely poor returns at high odds levels like lotto tickets.

The favorite-longshot bias means that the best wagers are on the biggest favorites. We want to use the win odds after adjustment for the track take to estimate the chance that a given odds horse will win. We use the following formula:

Probability that a horse at odds $O_{i}$ to 1 will win $=$ Track payback less breakage/Odds plus one. 
In symbols:

$$
q_{i}=\frac{Q}{O_{i}+1}
$$

where $q_{i}$ is the probability that a horse at odds of $O_{i}$ to 1 will win and $Q$ is the track payback less breakage.

Figure 1.6: Actual Chance of Winning Compared with the Crowd's Estimate of this Chance at Various Odds Levels for Horses in 2196 Races in New York in 1971. Source:

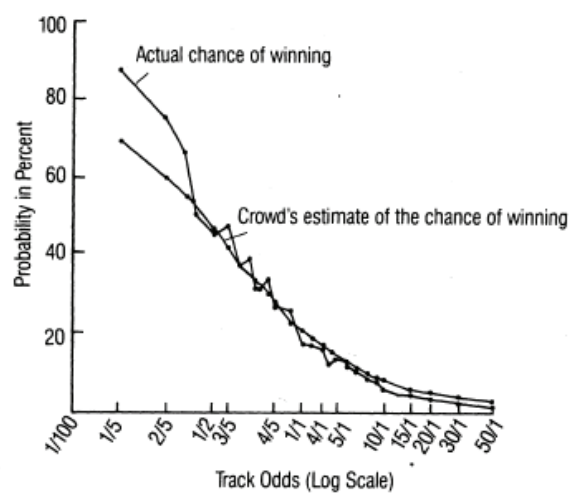

Quirin (1979).

Figure 1.6 shows how accurate the formula 1.1 is using the data in Quirin (1979) on 2196 thoroughbred races in New York in 1971 when the track payback was $83 \%$. The formula is quite accurate, although it is slightly off for the lowest and highest odds horses. We can see this clearly in Figure 1.7 which plots the first favorite to tenth favorite (the longest longshot) for 20,247 harness races at various tracks in 1970-1974. To make the formula 1.1 more accurate we adjust the track payback by the favorite-longshot bias and the average breakage as follows:

The probability that a horse at odds $O_{i}$ to 1 will win equals the track payback less breakage adjusted for the favorite-longshot bias/Odds plus one.

In symbols

$$
q_{i}=\frac{Q+D_{i}\left(O_{i}\right)}{O_{i}-1}
$$

where $q_{i}$ is the probability that a horse at odds of $O_{i}$ to 1 will win, $Q$ is the track payback less breakage and $D_{i}\left(O_{i}\right)$ is the adjustment for the favorite-longshot bias at this odds level. Table 1.5 and Figure 1.5 give these 


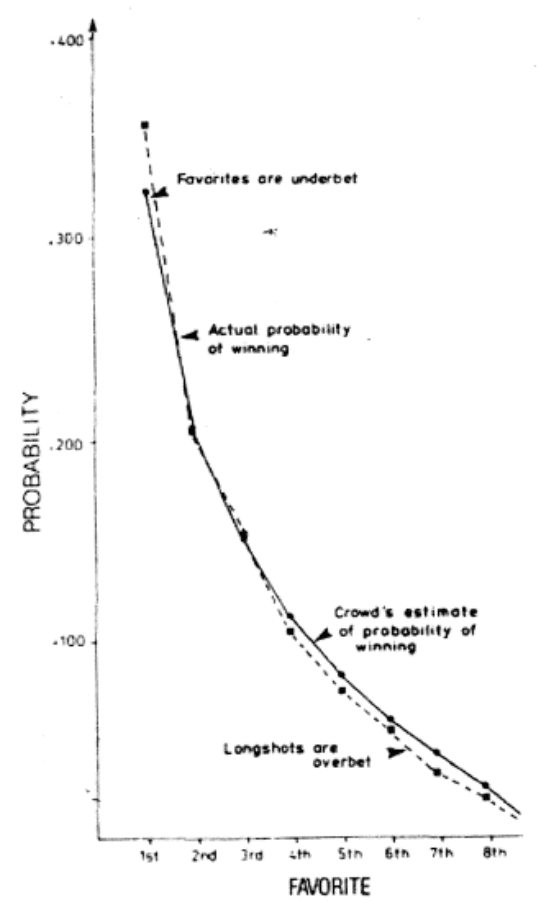

Figure 1.7: The actual probability of winning versus the crowd's odds estimate probability of winning for the 1st, 2nd, ...10th favorite in 20,247 harness horse races, 197074. Source: Ali (1979).

adjustments for California with a track take of $15.33 \%$ and New York with a track take of $17 \%$, respectively. Table 1.3 and Figure 1.8 give the probability of winning at the various odds levels in California and New York. These values are quite close to those at most tracks in North America because the track takes are either close to the $15.33 \%$ in California or the $16 \%$ in New York. Tracks in the United States generally have 10 cent breakage while those in Canada have 5 cent breakage. The effect of the lower breakage is to give a slightly higher payoff upon winning at the same odds level. So lower breakage is similar to a slightly higher probability of winning as shown in Table 1.3. You do not need to adjust Tables 3 and 4 much for your track if it is not in California or New York. Take the values closest to yours. They should be accurate enough for your betting purposes.

Since 1986 there have been a number of developments that have influenced the betting and have shifted these graphs such as:

1. There are no longer separate pools for individual races at different racetracks. All the races now have pooled betting which now comes in late with about half the bets not recorded in the pools until the race is already running; 
Table 1.3: The probability of winning in percent at various odds levels in California and New York in 1986 and 2016.

\begin{tabular}{|c|c|c|c|c|}
\hline \multirow{3}{*}{$\begin{array}{l}\text { Quoted } \\
\text { Odds }\end{array}$} & \multicolumn{2}{|c|}{1986} & \multicolumn{2}{|c|}{2016} \\
\hline & $\mathrm{Q}=84.67 \%$ & $\mathrm{Q}=83 \%$ & $\mathrm{Q}=84.67 \%$ & $\mathrm{Q}=84 \%$ \\
\hline & California & New York & California & New York \\
\hline Odds & Calif 1986 & NY 1986 & Calif 2016 & NY 2016 \\
\hline $1-20$ & & & 86.61 & 85.98 \\
\hline $1-10$ & 92.00 & 90.50 & 80.32 & 79.74 \\
\hline $1-5$ & 78.90 & 77.60 & 70.48 & 69.96 \\
\hline $2-5$ & 65.70 & 64.60 & 60.65 & 60.20 \\
\hline $3-5$ & 55.60 & 54.60 & 53.18 & 52.78 \\
\hline $4-5$ & 49.30 & 48.40 & 47.28 & 46.93 \\
\hline $1-1$ & 44.20 & 43.30 & 42.51 & 42.19 \\
\hline $6-5$ & 40.00 & 39.20 & 38.58 & 38.28 \\
\hline $7-5$ & 36.40 & 35.70 & 35.99 & 35.72 \\
\hline $8-5$ & 33.60 & 33.00 & 32.45 & 32.20 \\
\hline $9-5$ & 31.30 & 30.70 & 30.03 & 29.79 \\
\hline $2-1$ & 27.90 & 27.40 & 26.62 & 26.42 \\
\hline $5-2$ & 24.20 & 23.70 & 22.93 & 22.75 \\
\hline $3-1$ & 21.00 & 20.60 & 20.10 & 19.94 \\
\hline $7-2$ & 18.40 & 18.10 & 17.84 & 17.70 \\
\hline $4-1$ & 16.40 & 16.10 & 16.05 & 15.92 \\
\hline $9-2$ & 14.70 & 14.40 & 14.56 & 14.45 \\
\hline $5-1$ & 12.80 & 12.60 & 12.81 & 12.70 \\
\hline $6-1$ & 11.00 & 10.80 & 11.03 & 10.94 \\
\hline $7-1$ & 9.60 & 9.40 & 9.67 & 9.59 \\
\hline $8-1$ & 8.60 & 8.40 & 8.60 & 8.53 \\
\hline $9-1$ & 7.60 & 7.50 & 7.73 & 7.67 \\
\hline $10-1$ & 6.90 & 6.80 & 7.02 & 6.96 \\
\hline $11-1$ & 6.30 & 6.10 & 6.38 & 6.32 \\
\hline $12-1$ & & & 5.83 & 5.78 \\
\hline $13-1$ & 5.30 & 5.20 & 5.35 & 5.31 \\
\hline $14-1$ & 4.90 & 4.80 & 4.94 & 4.90 \\
\hline $15-1$ & 4.50 & 4.40 & 4.58 & 4.54 \\
\hline $16-1$ & 4.20 & 4.10 & 4.26 & 4.22 \\
\hline $17-1$ & 3.90 & 3.80 & 3.97 & 3.93 \\
\hline $18-1$ & 3.70 & 3.60 & 3.71 & 3.68 \\
\hline $19-1$ & 3.40 & 3.40 & 3.48 & 3.45 \\
\hline $20-1$ & 3.20 & 3.20 & 3.27 & 3.24 \\
\hline $21-1$ & 3.00 & 3.00 & 3.08 & 3.05 \\
\hline $22-1$ & 2.90 & 2.80 & 2.90 & 2.87 \\
\hline $23-1$ & 2.70 & 2.60 & 2.74 & 2.71 \\
\hline $24-1$ & 2.60 & 2.50 & 2.59 & 2.57 \\
\hline $25-1$ & 2.30 & 2.20 & 2.28 & 2.26 \\
\hline $30-1$ & 1.80 & 1.70 & 1.91 & 1.89 \\
\hline $35-1$ & 1.40 & 1.20 & 1.63 & 1.62 \\
\hline $40-1$ & 1.00 & 0.90 & 1.35 & 1.33 \\
\hline $50-1$ & 0.70 & 0.70 & 1.08 & 1.07 \\
\hline $60-1$ & 0.60 & 0.50 & 0.86 & 0.85 \\
\hline $70-1$ & 0.40 & 0.40 & 0.69 & 0.68 \\
\hline 80-1 & 0.30 & 0.30 & 0.57 & 0.56 \\
\hline $90-1$ & 0.30 & 0.20 & 0.47 & 0.46 \\
\hline $100-1$ & 0.10 & 0.10 & 0.38 & 0.38 \\
\hline $200-1$ & & & 0.15 & 0.15 \\
\hline
\end{tabular}




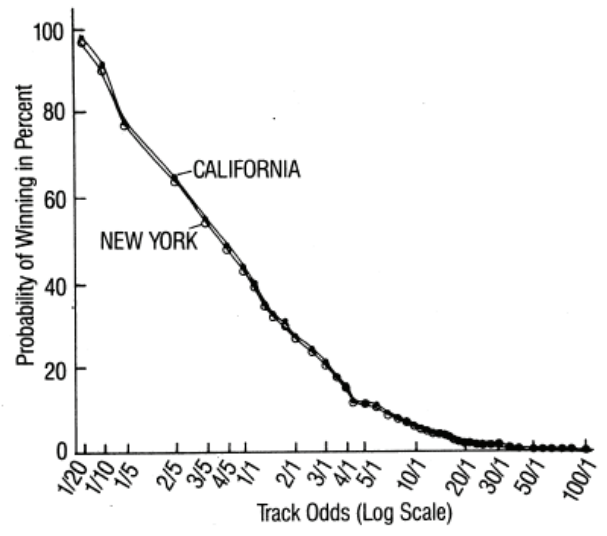

Figure 1.8: The probability of winning the race versus the track win odds in New York and California in 1986.

2. There are rebates where tracks send a signal with the results and the rebate shops and the track share the track commission between the rebate shop, the tracks and the bettors. So instead of facing 13-30\% transaction costs, large bettors are actually charged about $11-12 \%$ net; and

3. Betting shops such as Betfair, Pinnacle, Betdaq and others, offer long and short bets on racing and many other events such as political campaigns, etc.

Figure 1.9a-c look more closely at the extreme favorites in the US and the UK. Figure 1.9(c) shows that in Britain, bookies construct odds, creating the favorite-longshot bias to clear the market and equilibrate bettor demand.

Figure 1.10 shows that the bias curve may be different for different types of races. It shows the bias for the Kentucky Derby for 1903-1986. The better races may well have flatter biases. See Tompkins, Ziemba and Hodges (2008) and Ziegler and Ziemba (2015) who demonstrate similar biases in the S\&P500 and FTSE100 index futures options. I use such ideas in a futures fund and private investment accounts. These and other strategies tend to work and my futures fund has a very good risk-adjusted performance.

Figure 1.11 and its data in Table 1.4 show the bias based on more recent data. Observe that the favorites are no longer underbet enough to turn a profit betting them and the flatness of the curve until you get to fairly long priced horses. You can still short longshots on Betfair and other rebate shopsand make a profit if you are careful. Additional discussion and results are in Hausch and Ziemba (2008). 


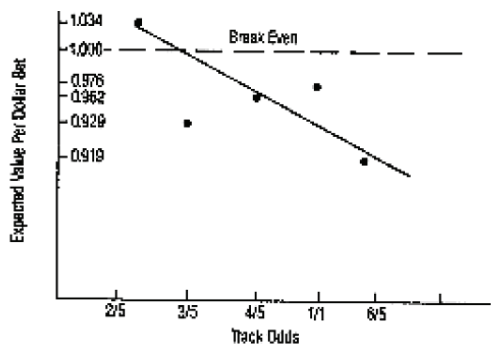

(a) Rates of return on extreme favorites in 1509 races run at various tracks during 1955-1962. Source: Fabricand (1965-1979)

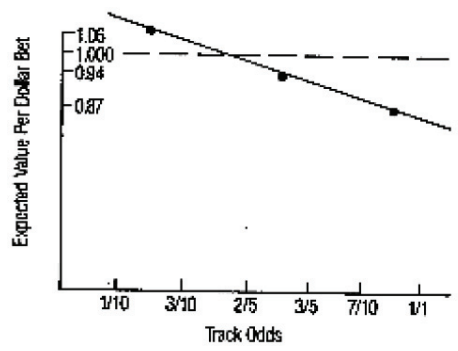

(b) Rates of return on extreme favorites in 233 races run in New York during 1955-1980. Source: Fabricand (19651979)

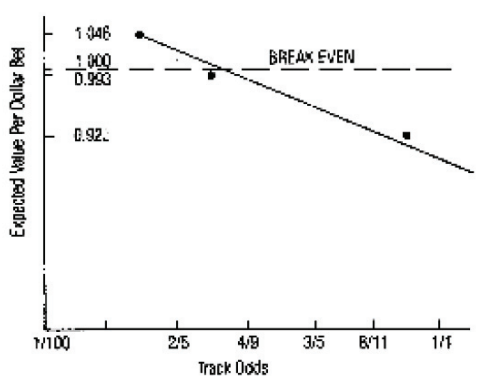

(c) Rates of return on extreme favorites in 1599 races run on British flat racing tracks in 1950, 1965 and 1973. Source: Figgis (1974) and Lord Rothschild (1978)

Figure 1.9: Extreme favorites used to provide small profits: see Ziemba and Hausch (1986) for these references.

Snowberg and Wolfers (2008) use the official jockey club data which has every US horse race run from 1992 to 2002. They group horses into 74 separate groups; which allows for fine distinctions, but also ensures sufficient observations to make good estimates of the rates of return to betting horses in each group.

The $\mathrm{x}$-axis of both figures inverts the odds so as to work out an implied probability, or, alternatively, how often a horse at those odds must win in order for the bettor to break even. Data are graphed on a log scale so as to better show the relevant range of 


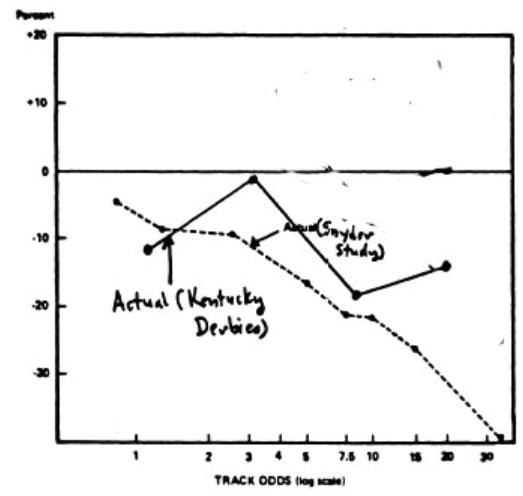

Figure 1.10: Expected return per dollar bet with and without the track take deducted for different odds levels in the Kentucky Derby 1903-1986 and in 35,285 races run during 1947-1975, from data in Snyder (1978). Source: Ziemba and Hausch (1987).

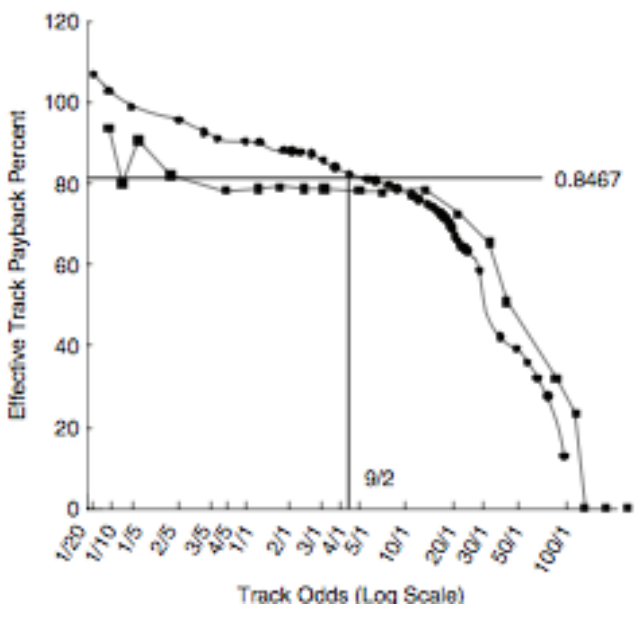

Figure 1.11: Effective track payback less breakage for various odds levels in California in 2008. Source: Ziemba and Hausch [1986] and Ziemba (2008).

the data. Figure 1.12a shows the actual rate of return to betting on horses in each category. These average rate of return for betting favorites is about $-10 \%$, while for horses at a mid-range of $1 / 1$ to $20 / 1$ yield a rate of return of $-20 \%$, and real longshots horses at $100 / 1$ or more are much more expensive to bet on, costing 60 cents per dollar bet. So they only return about $40 \%$ of the amount bet. This is, once again, the favorite-longshot bias. Figure 1.13 also shows the same pattern for the 54,013 races for which the jockey club recorded payoffs to exacta, quinella and trifectas bets. 
Table 1.4: Data for the effective track payback less breakage for various odds levels in California. Source: Ziemba and Hausch (1986) and Hausch and Ziemba (2008).

\begin{tabular}{rrrrrrr}
\hline Odds Level & Races & \multicolumn{1}{c}{ Avg Est Wins } & Wins & Total Est Wins & Fav/Longshot & Odds Range \\
\hline 1 & 9 & 0.952381 & 8 & 8.571429 & 0.933333287 & $1 / 20-1 / 12$ \\
2 & 54 & 0.9090909 & 41 & 49.0909086 & $0.8351851941 / 12-1 / 7.4$ \\
3 & 217 & 0.835003 & 163 & 181.195651 & $0.899580091 / 7.4-1 / 4.5$ \\
4 & 745 & 0.7660169 & 484 & 570.6825905 & $0.8481071761 / 4.5-1 / 2.7$ \\
5 & 5990 & 0.6582732 & 3197 & 3943.056468 & $0.8107923451 / 2.7-1 / 1.65$ \\
6 & 18250 & 0.5406803 & 8095 & 9867.415475 & $0.8203769291 / 1.65-1 / 1$ \\
7 & 35987 & 0.4260281 & 12561 & 15331.47323 & $0.8192950411 / 1-1.65 / 1$ \\
8 & 85716 & 0.3144652 & 22018 & 26954.69908 & $0.8168520051 .65 / 1-2.72 / 1$ \\
9 & 120483 & 0.2219781 & 21543 & 26744.58742 & $0.8055087812 .72 / 1-4.5 / 1$ \\
10 & 134990 & 0.14957 & 16371 & 20190.4543 & $0.8108287094 .5 / 1-7.4 / 1$ \\
11 & 136303 & 0.0966803 & 10827 & 13177.81493 & $0.8216081397 .4 / 1-12 / 1$ \\
12 & 113285 & 0.0614053 & 5504 & 6956.299411 & $0.79122528712 / 1-20 / 1$ \\
13 & 89063 & 0.0380625 & 2543 & 3389.960438 & $0.75015624720 / 1-33 / 1$ \\
14 & 63568 & 0.023571 & 976 & 1498.361328 & $0.65137826433 / 1-54.6 / 1$ \\
15 & 35808 & 0.0146932 & 281 & 526.1341056 & $0.53408436654 .6 / 1-90 / 1$ \\
16 & 9868 & 0.009349 & 28 & 92.255932 & 0.303503519 & $90 / 1-148.4 / 1$ \\
17 & 647 & 0.0059442 & 1 & 3.8458974 & $0.260017337148 .4 / 1-244.7 / 1$ \\
18 & 25 & 0.003213 & 0 & 0.080325 & & $0244.7 / 1-403.4 / 1$ \\
19 & 7 & 0.0020153 & 0 & 0.0141071 & $0403.4 / 1-665.1 / 1$ \\
20 & 3 & 0.0012285 & 0 & 0.0036855 & $065 / 1-1090.6 / 1$ \\
\hline
\end{tabular}

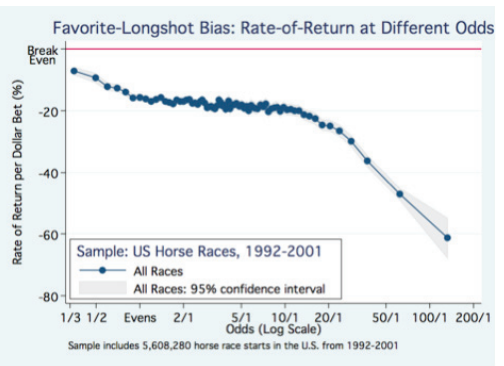

(a) The favorite-longshot bias, 19922001

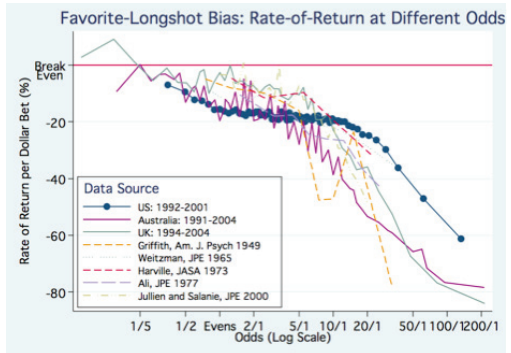

(b) Various favorite-longshot bias studies

Figure 1.12: Rate of return at different odds. Source: Snowberg and Wolfers (2008).

Hausch and Ziemba's (1995) data suggested that there were in fact positive rates of return to betting extreme favorites, perhaps suggesting limits to arbitrage. However, as the confidence intervals in Figures 1.13 show, there is substantially greater statistical uncertainty about returns on extreme favorites and longshots, and in none of these datasets is there a statistically signifyicant positive effect of betting on horses less than 0.2 to 1 . 


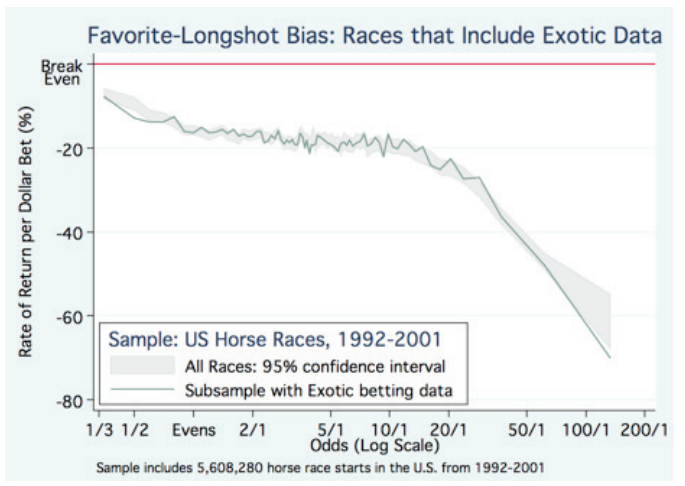

Figure 1.13: The Favorite-Longshot Bias in Different Subsets of Data Source: Snowberg and Wolfers (2008).

The data in Table 1.4 also confirms that betting extreme favorites to win loses less than the track take but now in 2016 does not produce positive gains

McGlothlin (1956), Ali (1977) and Ziemba and Hausch (1984, 1986, 1987) argue that the rate of return to betting longshots falls in the last race of the day. This conclusion was based on small samples, Thaler and Ziemba (1988), and Camerer (2001) interpret this as consistent with loss aversion: most bettors are losing at the end of the day, and the last race gives them a chance to leave the racetrack even for the day. Snowberg and Wolfers (2008) show that bettors underbet the favorite even more than usual, and overbet horses at odds that would make eliminate their losses around 8/1. Figure 1.14 replicates Figure 1.13, but separates out the last race of the day from earlier races. There is no statistically discernible difference between the last race and earlier races although the means are lower in this last race. If there were statistically significant evidence of loss aversion in McGlothlin or Ali's data, it no longer appears evident in more recent data, even though the favorite-longshot bias has persisted.

This bias forms part of the Kahneman-Tversky (1979) prospect theory where low probability events are overestimated and high probability events are underestimated. This also forms a part of the behavioral finance literature. Thaler and Ziemba (1988) discuss reasons for the bias as do Ziemba and Hausch $(1984,1987)$. These include the fact that there are more 


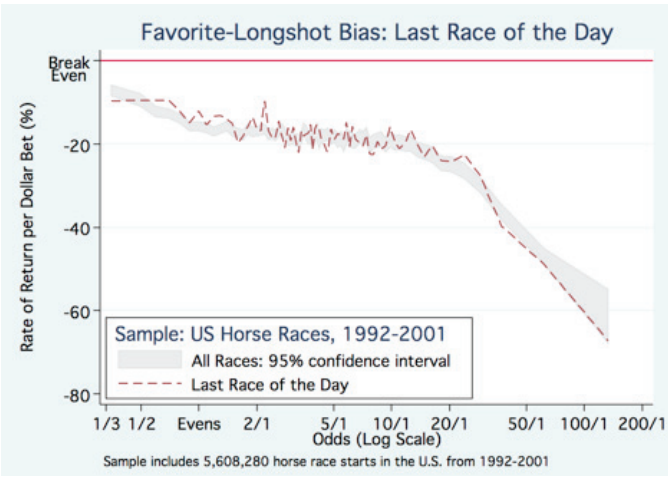

Figure 1.14: The Favorite-Longshot Bias in the Last Race vs. All Other Races. Source: Snowberg and Wolfers (2008).

bragging rights from picking longshots than from favorites: 50-1, wow was I smart while 2-5 is an easy pick. Transactions costs are another factor: bet $\$ 50$ to win $\$ 10$ is hardly worth the effort. A 1-10 horse having more than a $90 \%$ chance of winning has an expected value of about $\$ 1.03$ for every $\$$ bet, while a 100-1 horse has only an expected value of about 13.7 cents per dollar invested. The fair odds are about 700-1 not 100-1.

A typical use of the favorite-longshot bias is to correct probabilities for first, second and third. For first, we simply use

$$
q_{i}=\frac{Q+\Delta Q\left(O_{i}\right)}{O_{i}}
$$

where $q_{i}$ is the win fraction bet on $i$, namely $W_{i} / W$ the estimate that $i$ wins the race from the win pool, $Q$ is the track payback and $\Delta Q\left(O_{i}\right)$ is the favorite-longshot bias correlation at US odds $O_{i}$ to 1.

The Harville formulas are

$$
q_{i}=\frac{q_{i} q_{j}}{\left(1-q_{i}\right)} \quad \text { and } \quad q_{i j k}=\frac{q_{i} q_{j} q_{k}}{\left(1-q_{i}\right)\left(1-q_{i}-q_{j}\right)}
$$

are the probabilities of $i j$ and $i j k$ finishes assuming that $q_{j} /\left(1-q_{i}\right)$ is the probability that $j$ wins a race that does not contain $i$.

Similarly,

$$
\frac{q_{k}}{\left(1-q_{i}-q_{j}\right)}
$$

is the probability that $k$ wins a race that does not contain $i$ or $j$. 
Table 1.5: The Effective Track Payback Less Breakage for Various Odds Levels in California and New York, 1986 and 2016.

\begin{tabular}{|c|c|c|c|c|c|c|c|c|}
\hline Quoted & & & Adjustment & ETPI & 1986 & Adjustment & ETPI & 2016 \\
\hline Odds & Odds & Range & Fav-LS Bias & Calif & NY & Fav-LS Bias & Calif & NY \\
\hline $1-20$ & 0.05 & 0.09 & 20.8 & 104.5 & 104 & 8.00 & 92.67 & 92.00 \\
\hline $1-10$ & 0.1 & 0.19 & 20.3 & 104 & 102.3 & 7.30 & 91.97 & 91.30 \\
\hline $1-5$ & 0.2 & 0.39 & 18 & 101.7 & 100 & 6.60 & 91.27 & 90.60 \\
\hline $2-5$ & 0.4 & 0.59 & 14 & 97.7 & 96 & 6.00 & 90.67 & 90.00 \\
\hline $3-5$ & 0.6 & 0.79 & 10 & 93.7 & 92 & 5.47 & 90.14 & 89.47 \\
\hline $4-5$ & 0.8 & 0.99 & 9.1 & 92.8 & 91.1 & 4.93 & 89.60 & 88.93 \\
\hline $1-1$ & 1.0 & 1.19 & 8.2 & 91.9 & 90.2 & 4.40 & 89.07 & 88.40 \\
\hline $6-5$ & 1.2 & 1.39 & 7.3 & 91 & 89.3 & 3.86 & 88.53 & 87.86 \\
\hline $7-5$ & 1.4 & 1.49 & 6.4 & 90.1 & 88.4 & 3.33 & 88.00 & 87.33 \\
\hline $8-5$ & 1.6 & 1.79 & 6.3 & 90 & 88.3 & 2.79 & 87.46 & 86.79 \\
\hline $9-5$ & 1.8 & 1.99 & 6.2 & 89.9 & 88.2 & 2.26 & 86.93 & 86.26 \\
\hline $2-1$ & 2.0 & 2.49 & 6.1 & 89.8 & 88.1 & 1.72 & 86.39 & 85.72 \\
\hline $5-2$ & 2.5 & 2.99 & 6.1 & 89.8 & 88.1 & 1.19 & 85.86 & 85.19 \\
\hline $3-1$ & 3.0 & 3.49 & 4.5 & 88.2 & 86.5 & 0.65 & 85.32 & 84.65 \\
\hline $7-2$ & 3.5 & 3.99 & 3 & 86.7 & 85 & - & 84.67 & 84.00 \\
\hline 4-1 & 4.0 & 4.49 & 1.5 & 85.2 & 83.5 & -0.50 & 84.17 & 83.50 \\
\hline $9-2$ & 4.5 & 4.99 & 0 & 83.7 & 82 & -1.00 & 83.67 & 83.00 \\
\hline $5-1$ & 5.0 & 5.99 & -1.2 & 82.5 & 80.8 & -1.50 & 83.17 & 82.50 \\
\hline $6-1$ & 6.0 & 6.99 & -1.9 & 81.8 & 80.1 & -2.00 & 82.67 & 82.00 \\
\hline $7-1$ & 7.0 & 7.99 & -2.6 & 81.1 & 79.4 & -2.50 & 82.17 & 81.50 \\
\hline $8-1$ & 8.0 & 8.99 & -3.2 & 80.5 & 78.8 & -3.00 & 81.67 & 81.00 \\
\hline $9-1$ & 9.0 & 9.99 & -4.2 & 79.5 & 77.8 & -3.50 & 81.17 & 80.50 \\
\hline $10-1$ & 10 & 10.99 & -5.2 & 78.5 & 76.8 & -4.00 & 80.67 & 80.00 \\
\hline $11-1$ & 11 & 11.99 & -6.2 & 77.5 & 75.8 & -5.00 & 79.67 & 79.00 \\
\hline $12-1$ & 12 & 12.99 & -7.2 & 76.5 & 74.8 & -6.00 & 78.67 & 78.00 \\
\hline $13-1$ & 13 & 13.99 & -8.2 & 75.5 & 73.8 & -7.05 & 77.62 & 76.95 \\
\hline $14-1$ & 14 & 14.99 & -9.2 & 74.5 & 72.8 & -8.10 & 76.57 & 75.90 \\
\hline $15-1$ & 15 & 15.99 & -10.2 & 73.5 & 71.8 & -9.15 & 75.52 & 74.85 \\
\hline $16-1$ & 16 & 16.99 & -11.2 & 72.5 & 70.8 & -10.20 & 74.47 & 73.80 \\
\hline $17-1$ & 17 & 17.99 & -12.2 & 71.5 & 69.8 & -11.25 & 73.42 & 72.75 \\
\hline $18-1$ & 18 & 18.99 & -13.2 & 70.5 & 68.8 & -12.30 & 72.37 & 71.70 \\
\hline $19-1$ & 19 & 19.99 & -14.2 & 69.5 & 67.8 & -13.35 & 71.32 & 70.65 \\
\hline $20-1$ & 20 & 20.99 & -15.2 & 68.5 & 66.8 & -14.40 & 70.27 & 69.60 \\
\hline $21-1$ & 21 & 21.99 & -16.2 & 67.5 & 65.8 & -15.45 & 69.22 & 68.55 \\
\hline $22-1$ & 22 & 22.99 & -17.2 & 66.5 & 64.8 & -16.50 & 68.17 & 67.50 \\
\hline $23-1$ & 23 & 23.99 & -18.2 & 65.5 & 63.8 & -17.55 & 67.12 & 66.45 \\
\hline $24-1$ & 24 & 24.99 & -19.2 & 64.5 & 62.8 & -18.60 & 66.07 & 65.40 \\
\hline $25-1$ & 25 & 29.99 & -20.2 & 63.5 & 61.8 & -19.65 & 65.02 & 64.35 \\
\hline $30-1$ & 30 & 34.99 & -25.2 & 58.5 & 56.8 & -20.70 & 63.97 & 63.30 \\
\hline $35-1$ & 35 & 39.99 & -36 & 47.7 & 46 & -21.75 & 62.92 & 62.25 \\
\hline $40-1$ & 40 & 49.99 & -39.9 & 43.8 & 42.1 & -22.80 & 61.87 & 61.20 \\
\hline $50-1$ & 50 & 59.99 & -43.7 & 40 & 38.3 & -24.00 & 60.67 & 60.00 \\
\hline $60-1$ & 60 & 69.99 & -47.5 & 36.2 & 34.5 & -28.00 & 56.67 & 56.00 \\
\hline $70-1$ & 70 & 79.99 & -51.4 & 32.3 & 30.6 & -32.00 & 52.67 & 52.00 \\
\hline $80-1$ & 80 & 89.99 & -55.2 & 28.5 & 26.8 & -36.00 & 48.67 & 48.00 \\
\hline $90-1$ & 90 & 99.99 & -59 & 24.7 & 23 & -40.00 & 44.67 & 44.00 \\
\hline $100-1$ & 100 & 110 & -70 & 13.7 & 12 & -44.00 & 40.67 & 40.00 \\
\hline $200-1$ & 200 & 220 & & & & -52.00 & 32.67 & 32.00 \\
\hline
\end{tabular}


These formulas are handy but are biased because favorites do not come in second and third as much as these formulas indicate. So a correction can be used to decrease the second and third probabilities for the favorites and increase it for the longer priced horses. This is called discounted Harville. One decays $q_{i}$ by a coefficient $\alpha$ about 0.81 . So

$$
r_{i}=\frac{q_{i}^{\alpha}}{\sum q_{i}^{\alpha}}
$$

are used instead of $q_{i}$ for second and $\alpha=(0.81)^{2} \cong 0.64$ is used for third.

So

$$
q_{i j}=\frac{q_{i} r_{j}}{\left(1-r_{j}\right)} \quad \text { and } \quad q_{i j k}=\frac{q_{i} r_{j} s_{k}}{\left(1-r_{i}\right)\left(1-s_{i}-s_{j}\right)}
$$

where the

$$
s_{i}=\frac{q_{i}^{0.64}}{\sum q_{i}^{0.64}} .
$$

Then these formulas give accurate $i j k$ probabilities for various bets involving multiple horses. More on these biases and their correction is in Hausch, Lo, and Ziemba (2008). These formulas allow us to update Table 1.5 above to be more accurate. That yields Table 1.5. For the 1986 data, the track take is $15.33 \%$ ( $17 \%$ New York) for an average payback of 84.67 cents per dollar wagered $(83 \%)$. Breakage is to the nearest 10 cents below the true computed amount per dollar wagered. At 9-2, the breakeven point in the favorite-longshot bias, breakage amounts to about another $1 \%$ commission. For the 2016 data, I used the data from Table 1.4 and Figure 1.12. This data covers the period from 1992 to 2001 . It is assumed that 2016 is similar. The breakeven point is at 7 to 2 , and, as you see, none of the odds levels provide a flat bet profit. The take in New York was $16 \%$ and the take in California was $15.33 \%$. 